\title{
Clinical Risk Factors of Stomal Recurrence in Patients Requiring Emergency Tracheostomy for Advanced Laryngeal Cancer
}

\author{
C Ndiaye ${ }^{*}$, H Ahmed ${ }^{1}$, EJR Palou ${ }^{2}$, E S Diom ${ }^{1}$, S Maiga ${ }^{1}$, MW Barry², N Pilor ${ }^{1}$, A Mbaye ${ }^{1}$, N Ndour ${ }^{1}$ and IC Ndiaye ${ }^{1}$ \\ ${ }^{1}$ ENT Department in FANN Teaching Hospital, Dakar, Senegal
}

${ }^{2}$ ENT Department in Diamnadio's Children Hospital, Dakar, Senegal

*Corresponding author: C Ndiaye, ENT Department in FANN Teaching Hospital, Dakar, Senegal

\begin{abstract}
Background: The aim of this work is to study the impact of tracheostomy on peristomal recurrence in patients undergoing primary laryngectomy.

Methods: This was a retrospective study from January 1, 2009 to December 31, 2013. All patients with laryngeal cancer classified T3 or T4 were included. The patients were divided into 2 groups. One group was formed by patients underwent tracheostomy then primary laryngectomy, the « T+LT » group. Second group was constituted by patients underwent primary laryngectomy « LT only ». The tracheostomy, the subglottic extension, the resection margins and the tumor stage were studied. The exact Fisher test was used to compare the variables. A value of $\mathrm{p}<0.05$ was significant.

Results: Ninety four patients were enrolled in this study. The «T + LT» group represented $61.7 \%(n=58)$ and the «LT only» group 38.3\% ( $\mathrm{n}=36)$. Peristomal recurrences represented $25 \%$ of recurrences. Patients in both groups did not differ by age $(\mathrm{p}=$ $0.53)$, sex $(p=1)$, tumor stage $(p=0.8)$ and lymph node extension $(p=0.87)$. The tracheostomy $(p=0.73)$, the advanced stage $(p=$ $0.15)$, the pathological resection margins (0.68) and the subglottic extension (0.35) were not associated with recurrence peristomal.

Conclusion: Tracheostomy is not a risk factor for peristomal recurrence after primary laryngectomy. In the unavailability of a laser, the ENT surgeon is able to perform a tracheostomy without compromise the patient's prognosis.
\end{abstract}

Keywords: Laryngectomy; Peristomal Recurrence; Laryngeal Cancer

\section{Introduction}

Laryngeal cancer is the second cancer managed in the ENT department of the FANN University Hospital Center. According to the World Health Organization, it was the second cancer of upper aerodigestive tract [1]. In our context, the practice of head and neck oncology is characterized by a delay of diagnosis, a lack of specialists and equipment [2]. More patients consult at advanced stages. Thus, a tracheostomy is performed for laryngeal dyspnea. This tracheotomy is often incriminated in the occurrence of peristomal recurrence [3]. From the 1960s to today, many articles have been published on the subject, but the controversy remains about the responsibility of tracheostomy in peristomal recurrence
$[4,5]$. The aim of this work is to study the impact of tracheostomy on peristomal recurrence in patients with primary laryngectomy.

\section{Methods}

We conducted a retrospective, descriptive and analytical study from January 1st, 2009 to December 31st, 2013 in the ENT departments of Dakar University Hospital Centers. We included all patients presenting a curable laryngeal cancer and classified T3 or T4 stage. Tracheostomy was performed urgently for a severe laryngeal dyspnea. All patients had total laryngectomy with resection of the tracheostome and associated with bilateral lymph node dissection. This was a primary laryngectomy different 
to salvage laryngectomy which performed after failure of the laryngeal preservation protocol. No patient in our series had salvage laryngectomy. A hemithyroidectomy is performed in case of subglottic extension. Radiotherapy was not systematic for all patients. We considered recurrence when the cancer appear on 6 months after laryngectomy. This recurrence was peristomal when it located around or in the tracheostome. It was regional if it concerned lymph nodes areas. The patients were divided on 2 groups: A group of patients who had a tracheostomy followed a total laryngectomy which called the "T + LT" group, and another group of patients who underwent total laryngectomy alone without tracheostomy called "LT only" group. The dependent variable was peristomal recurrence and the independent variables were: tracheostomy, subglottic extension, resection margins, and tumor stage. Fisher's exact test was used to compare the qualitative variables. A value of $p<0.05$ was considered significant.

\section{Results}

Table 1: Distribution of patients according to the location of recurrence.

\begin{tabular}{|c|c|}
\hline Recurrence & Number of Patients \\
\hline Pharyngeal & 13 \\
\hline Regionals & 10 \\
\hline Stomal & 9 \\
\hline Metastasis & 4 \\
\hline Total & 36 \\
\hline
\end{tabular}

Table 2: Characteristics of patients in both groups.

\begin{tabular}{|c|c|c|c|}
\hline & $T+L T(n=58)$ & LT only ( $n=36)$ & P-value \\
\hline \multicolumn{4}{|c|}{ Sex } \\
\hline Male & 57 & 35 & 1 \\
\hline Female & 1 & 1 & \\
\hline \multicolumn{4}{|c|}{ Age (Years) } \\
\hline$<60$ & 33 & 18 & 0,53 \\
\hline$>60$ & 25 & 18 & \\
\hline \multicolumn{4}{|c|}{ P T Stage } \\
\hline T3 & 38 & 25 & 0,8 \\
\hline $\mathrm{T} 4$ & 20 & 11 & \\
\hline \multicolumn{4}{|c|}{ P NO/N+ } \\
\hline No & 28 & 18 & 0,87 \\
\hline $\mathrm{N}+$ & 30 & 18 & \\
\hline
\end{tabular}

The series constituted of 94 patients. The $\mathrm{T}+\mathrm{LT}$ group represented $61.7 \%(n=58)$ and the LT only group $38.3 \%(n=36)$. The male gender represented $97.87 \%$ of patients. The average age of patients was 59 years (standard deviation: 9 years). Thirty-six patients $(38.3 \%)$ had a recurrence. The median time to recurrence was 9 months with extremes of 6 and 29 months. The median time to onset of peristomal recurrence was 10 months with extremes of 6 and 29 months. Peristomal recurrence represented 25\% of recurrences (Table 1). Patients in both groups (LT only and T + LT) did not differ according to age, sex, tumor stage and lymph node extension (Table 2). Tracheostomy, advanced stage, margins resection, and subglottic extension were not associated with peristomal recurrence (Table 3).

Table 3: Factors associated with stomal recurrence.

\begin{tabular}{|c|c|c|c|}
\hline & Stomal & recurrence & P -value \\
\hline & Yes & No & \\
\hline \multicolumn{4}{|c|}{ Tracheostomy } \\
\hline Yes & 5 & 53 & 0,73 \\
\hline No & 4 & 32 & \\
\hline \multicolumn{4}{|c|}{ Tumoral Stage } \\
\hline P T4 & 5 & 26 & 0,15 \\
\hline Р T3 & 4 & 59 & \\
\hline \multicolumn{4}{|c|}{ Sub-Glottic Extension } \\
\hline Yes & 9 & 69 & 0,35 \\
\hline No & 0 & 16 & \\
\hline \multicolumn{4}{|c|}{ Margins of Resection } \\
\hline Negatives & 8 & 74 & 0,68 \\
\hline Positives & 1 & 11 & \\
\hline
\end{tabular}

\section{Discussion}

Peristomal recurrence after primary laryngectomy occurs in 2 to $15 \%$ of cases $[4,6]$. Several mechanisms have been described pathological resection margins, paratracheal node recurrence, dissemination of cancer around the tracheostomy [6]. However, the responsibility for tracheostomy in stomal or peristomal recurrence is controversial. Since the 1960s until today many articles evoked the subject. There has never been consensus about the impact of tracheostomy in peristomal recurrence. In the 1960s Keim and Stell identified tracheotomy as a factor in peristomal recurrence $[4,7]$. In contrast to the two authors cited above, in the same period, Modlin did not showed any relationship between tracheostomy and recurrence [5]. More recently, Onakoya PA et al. reported that tracheotomy was associated with a risk of peristomal recurrence [8]. However, none of these authors had performed any statistic test. The introduction of chemotherapy and radiotherapy in the treatment of laryngeal cancer modified the therapeutic strategy [9]. This is the era of laryngeal preservation protocol. The consequence of this new protocol is the appearance of the concept of "salvage laryngectomy" indicated in case of the failure of the conservative treatment. Thus a more recent series, associate patients who had a primary laryngectomy and those had secondary laryngectomy, concluded that the tracheotomy increased the risk of peristomal recurrence [10]. 
In our opinion, this series because of its diversity would not reflect the impact of tracheostomy on peristomal recurrence. Indeed, the irradiation of patients in case of the laryngeal preservation protocol could constitute a statistical bias. In addition, the failure of conservative treatment could predict a local advanced or aggressive cancer. In our case, such as the recent series composed only of case of primary laryngectomy, tracheostomy did not impact on peristomal recurrence [11-13]. Furthermore the large tumors, subglottic extension and pathological resection margins weren't risk factors for peristomal recurrence (Table 3). The analyse of results from differents series in the literature is difficult because the methodologies used are differents. Despite our result, that tracheotomy is not associated with peristomal recurrence, we continued to suggest some classics rules of laryngeal oncologic surgery. We argued, like others authors, to place the tracheostomy high and to resect the tracheostomy at time of larygectomy [4]. Some authors proposed the debulking by laser for avoid the tracheostomy. According to Hassani DA, et al. [14] laser surgery has theoretical oncological advantages, as it prevents disruption to tissue planes and minimises the chance of tumour seeding, it intuitively is not quite as safe as a tracheostomy in terms of securing the airway as there remains the potential risk of post-operative oedema. Despite thus, the laser must be proposed in first intention if the equipment is available. Tracheostomy can make airway free. Besides it's a fast surgery, needs little instruments and realizing in all operating room.

\section{Conclusion}

The impact of tracheostomy on stomal recurrence is variously appreciated in literature. This is due from the criteria of inclusion and the statistical methods differents between the series. We hope, our results give insurance to the surgeon that tracheostomy is not associated with stomal recurrence after primary laryngectomy.

\section{References}

1. Barnes L, Eveson JW, Reichart P, Sidransky D (2005) World Health Organization Classification of Tumors: Pathology and Genetics of Head and Neck Tumors. Lyon: IARC press 9.

2. R Diouf, E Diop, I C Ndiaye (1991) Limites à l'exercice de la carcinologie cervico-faciale en Afrique Noire: l'exemple des cancers du larynx. Revue de Laryngologie 112(5): 423-427.

3. R Mantravadi, AM Katz, EM Sholnik (1981) Stomal recurrence. Arch Otolaryngol 107(12): 735-738.

4. Keim WF, Shapiro MJ, Rosin HD (1965) Study of post laryngectomy stomal recurrence. Arch Otolaryngol 81:183-186.

5. Modlin B, Ogura JH (1969) Post laryngectomy tracheal stomal recurrences. Laryngoscope 79(2): 239-250.

6. Leon X, Quer M, Burgues J, Abello P, Vega M, et al. (1996) Prevention of stomal recurrence. Head Neck 18(1): 54-59.

7. Stell PM, Van Den Broek P (1971) Stomal recurrence after laryngectomy: aetiology and management. J Laryngol Otol 85(2): 131-140.

8. Onakoya PA, Nwaorgu OG, Kokong DD, Adeosun AA, Ayodele KJ (2004) Stomal recurrence post laryngectomy in University College Hospital, Ibadan. Afr J Med Med Sci 33(1): 65-68.

9. (1991) Induction chemotherapy plus radiation compared with surgery plus radiation in patients with advanced laryngeal cancer. The Department of Veterans Affairs Laryngeal Cancer Study Group. N Engl J Med 324(24): 1685-1690.

10. Basheeth N, O'Leary G (2015) Oncologic outcomes of total laryngectomy: Impact of margins and preoperative tracheostomy. Head \& Neck 37: 862-868.

11. Pezier TF, Nixon IJ, Joshi A, Pang L, Oakley R, et al. (2013) Pre-operative tracheostomy does not impact on stomal recurrence and overall survival in patients undergoing primary laryngectomy. European Archives of Oto-Rhino-Laryngology 270(5): 1729-1735.

12. Fagan JJ, Loock JW (1996) Tracheostomy and peristomal recurrence. Clin Otolaryngol Allied Sci 21(4): 328-330.

13. Mohamed S Taha, Reda Sabra, Tarek A, Magdy A Riad (2014) Impact of preoperatative tracheostomy on tracheostome recurrence and overall survival in patients undergoing laryngectomy. The Egyptian Journal of Otolaryngology 30(4): 332-336.

14. Hassani DA, Bhananker SM (2006) Postoperative airway obstruction after airway tumor debulking. J Anesth 20(3): 237-239.

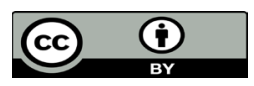

This work is licensed under Creative Commons Attribution 4.0 License

To Submit Your Article Click Here: Submit Article

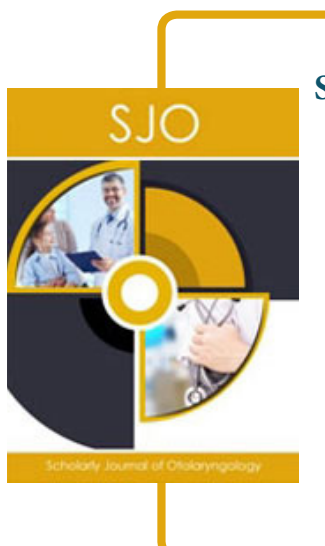

Scholarly Journal of Otolaryngology

\section{Assets of Publishing with us}

- Global archiving of articles

- Immediate, unrestricted online access

- Rigorous Peer Review Process

- Authors Retain Copyrights

- Unique DOI for all articles 